Supporting Information

\title{
Leveraging Nanoparticle Dispersion State to Tune Vanadium Ion Selectivity of Nanophase-Segregated Ionomer Nanocomposites for Redox Flow Batteries
}

Allison Domhoff ${ }^{1}$, Apoorv Balwani ${ }^{1}$, Tyler B. Martin ${ }^{2}$, and Eric M. Davis ${ }^{1, *}$

${ }^{1}$ Department of Chemical and Biomolecular Engineering, Clemson University, Clemson, SC 29634

${ }^{2}$ National Institute for Standards and Technology (NIST) Center for Neutron Research, Gaithersburg, MD 20899

*To whom correspondence should be addressed; Email: ericd@clemson.edu 


\section{Silica Nanoparticle (SiNP) Surface Functionalization}

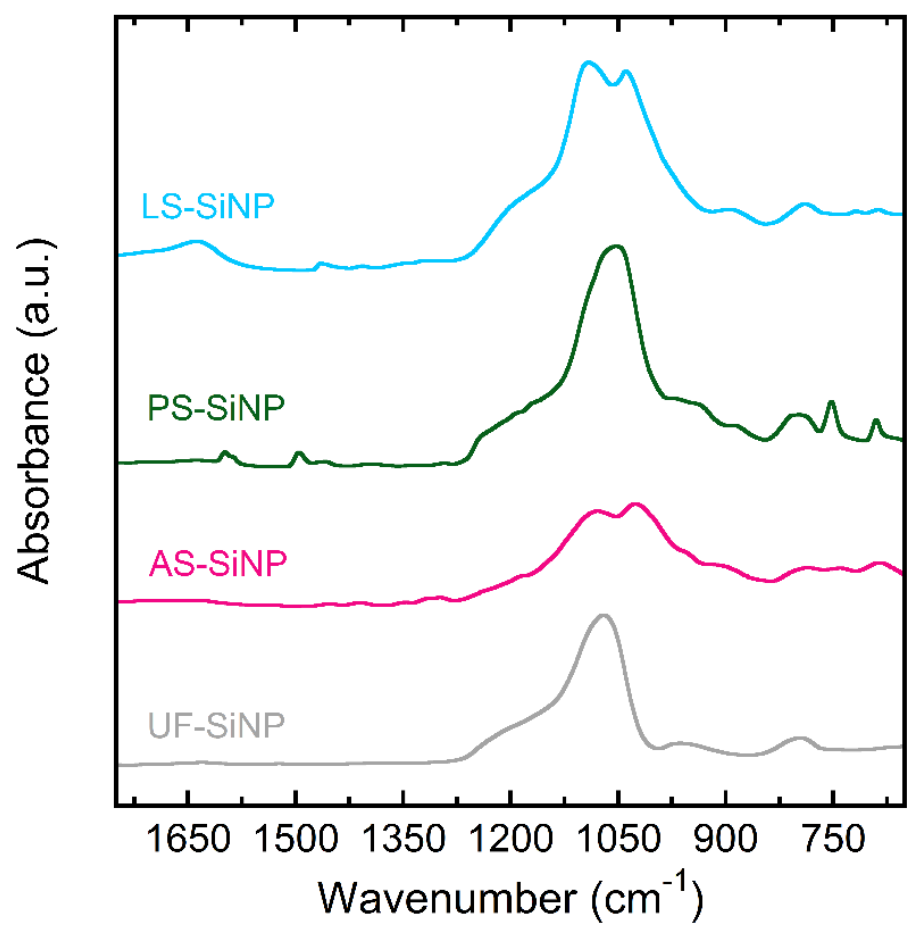

Figure S1. FTIR spectra of UF-SiNP (solid gray line), AS-SiNP (solid pink line), PS-SiNP (solid green line), and LS-SiNP (solid light blue line). The spectra have been shifted for clarity.

Figures S1 shows the FTIR spectra of unmodified silica nanoparticles (UF-SiNP) and sulfonic acid-functionalized SiNPs. As seen in Figure S1, the FTIR spectrum of UF-SiNP (solid gray line in Figure S1), demonstrates the expected peaks for silica that can be attributed to the stretching modes of the $\mathrm{Si}-\mathrm{O}-\mathrm{Si}\left(1200 \mathrm{~cm}^{-1}\right.$ to $\left.1000 \mathrm{~cm}^{-1}\right)$, Si-OH $\left(964 \mathrm{~cm}^{-1}\right)$, and $\mathrm{Si}-\mathrm{O}\left(797 \mathrm{~cm}^{-1}\right)$ groups. $^{1-}$ ${ }^{5}$ As these nanoparticles were utilized in all functionalizations, these characteristic peaks are also present in all of the functionalized NP spectra shown in Figure S1.

However, the spectrum of AS-SiNP (solid pink line in Figure S1) shows additional peaks at $1454 \mathrm{~cm}^{-1}$ and $1410 \mathrm{~cm}^{-1}$, which are attributed to the $\mathrm{H}-\mathrm{C}-\mathrm{H}$ scissoring mode, as well as peaks at $1298 \mathrm{~cm}^{-1}$ and $740 \mathrm{~cm}^{-1}$, which are attributed to the $\mathrm{Si}-\mathrm{CH}_{2}$ stretching and $\mathrm{H}-\mathrm{C}-\mathrm{H}$ rocking, respectively. Furthermore, the additional strong peak observed in the spectrum of AS-SiNP at 1079 
$\mathrm{cm}^{-1}$ is indicative of the $\mathrm{S}=\mathrm{O}$ stretching mode for AS-SiNP. Similar to the spectrum of AS-SiNP, the FTIR spectrum of LS-SiNP (solid light blue line in Figure S1) shows infrared bands at 1465 $\mathrm{cm}^{-1}, 1407 \mathrm{~cm}^{-1}, 1317 \mathrm{~cm}^{-1}$, and $719 \mathrm{~cm}^{-1}$, which can be assigned to the same modes as listed for AS-SiNP. In addition, the spectrum of LS-SiNP also shows an additional IR band around 1091 $\mathrm{cm}^{-1}$, which again, can be attributed to the $\mathrm{S}=\mathrm{O}$ stretching mode. These presence of these peaks confirms successful functionalized of the SiNP surface with sulfonic acid groups. ${ }^{3,6,7}$

The spectrum of the PS-SiNP (solid green line in Figure S1) shows IR peaks characteristic of the phenyl ring stretching and bending modes; specifically peaks located at $1599 \mathrm{~cm}^{-1}, 1496 \mathrm{~cm}^{-1}$, $1459 \mathrm{~cm}^{-1}, 753 \mathrm{~cm}^{-1}$, and $691 \mathrm{~cm}^{-1}$ (last two wavenumbers are representative of the 1,2,4trisubstituted phenyl ring). ${ }^{1}$ Furthermore, the peak located at $1398 \mathrm{~cm}^{-1}$ confirms the presence of $\mathrm{C}-\mathrm{O}$ bonds. Note, while the IR band associated with $\mathrm{S}=\mathrm{O}$ stretching is less pronounced when compared to the spectrum of AS-SiNP, it can still be observed as a shoulder broadening on the $\mathrm{Si}-\mathrm{O}-\mathrm{Si}$ peak centered around $1150 \mathrm{~cm}^{-1}$. Though not depicted in Figure S1, the presence of IR peaks around $2900 \mathrm{~cm}^{-1}$ were observed in the spectra of the LS-SiNP, AS-SiNP, and PS-SiNP and can be assigned to alkyl bridging groups on the surface of the SiNP.

Figure S2 shows the FTIR spectra of the amine-functionalized SiNPs. The spectral range is expanded in Figure $\mathrm{S} 2$ to highlight the presence of IR bands associated with both the alkyl groups in the bridging chains $\left(\approx 2900 \mathrm{~cm}^{-1}\right.$ for $\mathrm{C}-\mathrm{H}$ and $\left.\mathrm{H}-\mathrm{C}-\mathrm{H}\right)$, as well as the large, broad IR peak associated with $\mathrm{N}-\mathrm{H}$ stretching (centered around $3400 \mathrm{~cm}^{-1}$ ). Additionally, the IR peak at $\approx 1630 \mathrm{~cm}^{-1}$, which can be seen for all amine-functionalized SiNPs, can be attributed to the $\mathrm{H}-\mathrm{N}-\mathrm{H}$ bending vibrational mode in primary amines. The spectrum of the AA-SiNP (solid red line in Figure S2) also shows IR peaks at $1488 \mathrm{~cm}^{-1}$ and $1435 \mathrm{~cm}^{-1}$, which can be attributed to the 


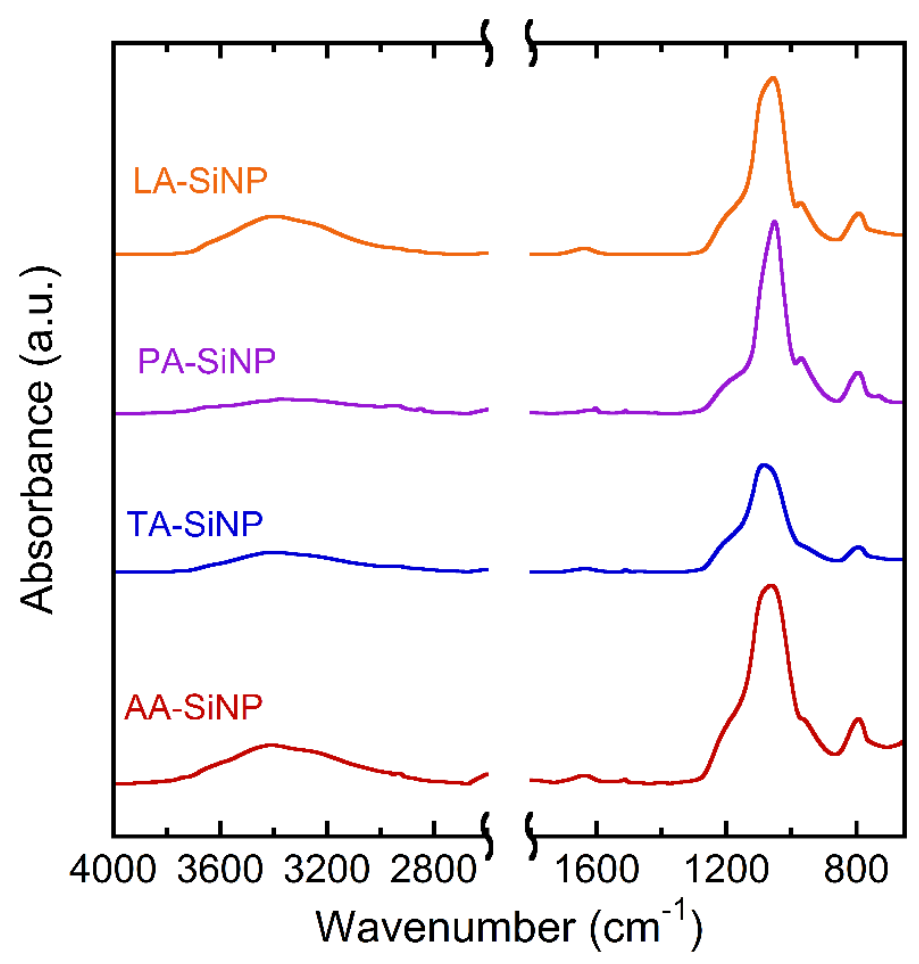

Figure S2. FTIR spectra of AA-SiNP (solid red line), TA-SiNP (solid blue line), PA-SiNP (solid purple line), and LA-SiNP (solid orange line). The spectra have been shifted for clarity.

$\mathrm{H}-\mathrm{C}-\mathrm{H}$ scissoring vibrational mode, as well as another peak at $1329 \mathrm{~cm}^{-1}$, which can be attributed to the $\mathrm{Si}-\mathrm{CH}_{2}$ stretching vibrational mode., ${ }^{2,4}$ Similarly, the FTIR spectrum of LA-SiNP (solid orange line in Figure S2) shows an IR band around $1468 \mathrm{~cm}^{-1}$, which again is attributed to the H$\mathrm{C}-\mathrm{H}$ scissoring vibrational mode. Unlike the other amine surface functionalizations, the IR spectrum of TA-SiNP (solid blue line in Figure S2) shows an additional peak at $1510 \mathrm{~cm}^{-1}$, representing a secondary $\mathrm{N}-\mathrm{H}$ stretching mode. This secondary vibrational mode arises from the multiple amine groups along the bridging chain. Finally, the spectrum of PA-SiNP (solid purple line in Figure S2) shows additional IR peaks at $1602 \mathrm{~cm}^{-1}$ and $1510 \mathrm{~cm}^{-1}$, which are attributed to the phenyl ring in the bridging chain, as well as a peak at $731 \mathrm{~cm}^{-1}$, which can be attributed to bonds in a disubstituted phenyl ring. ${ }^{5}$ 


\section{Nanocomposite Membrane Properties: Ion Exchange Capacity (IEC) and Acid Uptake}

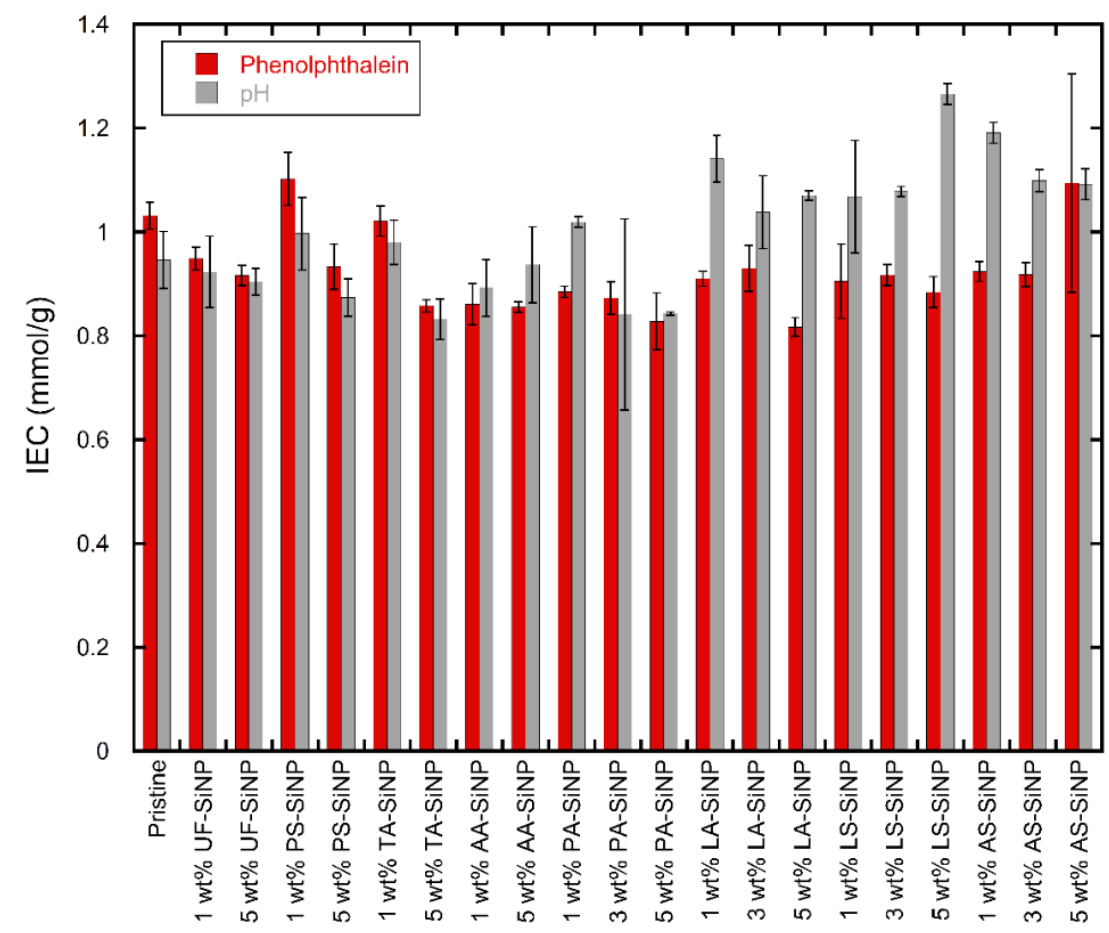

Figure S3. Ion exchange capacity (IEC) of pristine Nafion compared to Nafion nanocomposite membranes of differing nanoparticle surface functionality and nanoparticle loading, measured by both titration method (red) and $\mathrm{pH}$ method (gray).

Figure S3 shows the IEC of Nafion nanocomposite membranes compared to pristine Nafion membranes. IEC is a ratio between mmol of sulfonic acid groups to the dry weight of the membrane and provides a measure of the accessible sulfonic acid groups in the ionomer. The IEC for these membranes was determined using a previously described method. ${ }^{8,9}$ Briefly, the membranes were cast, annealed, and then dried at $80{ }^{\circ} \mathrm{C}$ for $24 \mathrm{~h}$, before being massed and immersed in $1 \mathrm{~mol} \mathrm{~L}^{-1} \mathrm{NaCl}$ for $24 \mathrm{~h}$. The membranes were then removed from the solution, and the $\mathrm{pH}$ of the remaining solution was measured to determine the volume of $0.01 \mathrm{~mol} \mathrm{~L}^{-1} \mathrm{NaOH}$ necessary to neutralize the solution. Additionally, the solution was titrated with $0.01 \mathrm{M} \mathrm{NaOH}$ and 
phenolphthalein ( $1 \%$ mass/volume in a mixture of $1: 1$ water/ethanol). The IEC was then calculated as follows

$$
\mathrm{IEC}=\frac{\mathrm{V}_{\mathrm{NaOH}} \mathrm{C}_{\mathrm{NaOH}}}{\mathrm{m}_{\mathrm{dry}}},
$$

where $\mathrm{V}_{\mathrm{NaOH}}$ is the volume of the $\mathrm{NaOH}$ solution in $\mathrm{L}, \mathrm{C}_{\mathrm{NaOH}}$ is the concentration of the $\mathrm{NaOH}$ solution in $\mathrm{mol} \mathrm{L}^{-1}$, and $\mathrm{m}_{\mathrm{dry}}$ is the dry mass of the membrane in $\mathrm{g}$. Although the titration method is more common in literature, it introduces inherent errors (including phenolphthalein color change occurring at $\mathrm{pH} \approx 8$, human error during titration, etc.) that can be minimized by calculating this volume from the initial $\mathrm{pH}$ of the solution. Discussions here, as well as in the manuscript, compare IEC values obtained by the $\mathrm{pH}$ method.

The addition of SiNPs functionalized with different surface moieties can affect the IEC in a number of ways, including: (1) sequestering the sulfonic acid groups of Nafion; (2) altering ionic network formation; or (3) introducing more sulfonic acid groups into the membranes. The introduction of more sulfonic acid groups into the membranes (by addition of sulfonic acid functionalized SiNP) is expected to increase the IEC as compared to that of pristine Nafion. The introduction of amine groups into the membrane (by addition of the amine functionalized SiNP) is expected to reduce the IEC compared to pristine Nafion, as the amine groups can sequester the sulfonic acid groups of Nafion, altering the ionic network formation. As described in the manuscript, all nanocomposite membranes with SiNPs at $w_{\mathrm{NP}}=1 \%$, regardless of surface chemistry, showed increased vanadium ion permeability with respect to pristine Nafion. The IEC of each nanocomposite film with SiNPs at $w_{\mathrm{NP}}=1 \%$ all increase or remain the same (within error) of pristine Nafion, so it follows, according to the Donnan principle, that the vanadium ion 
permeability also increases according. Similarly, all films with sulfonic-acid functionalized SiNPs and LA-SiNP that demonstrated increased vanadium ion permeability also demonstrated increased IEC. Nanocomposite membranes with PA-SiNP and TA-SiNP at the highest SiNP loading $\left(w_{\mathrm{NP}}=5 \%\right)$, show reduced or similar IEC values to that of pristine Nafion, while films containing AA-SiNP at $w_{\mathrm{NP}}=3 \%$ and at $w_{\mathrm{NP}}=5 \%$ demonstrated IEC values that were within the error of the calculated IEC for pristine Nafion. While these IEC values coincide with general predictions from the Donnan principle, changes in vanadium ion permeability for every nanocomposite membrane do not follow the expected trends set by the Donnan principle, indicating there are other factors influencing vanadium ion permeability through the membranes. 


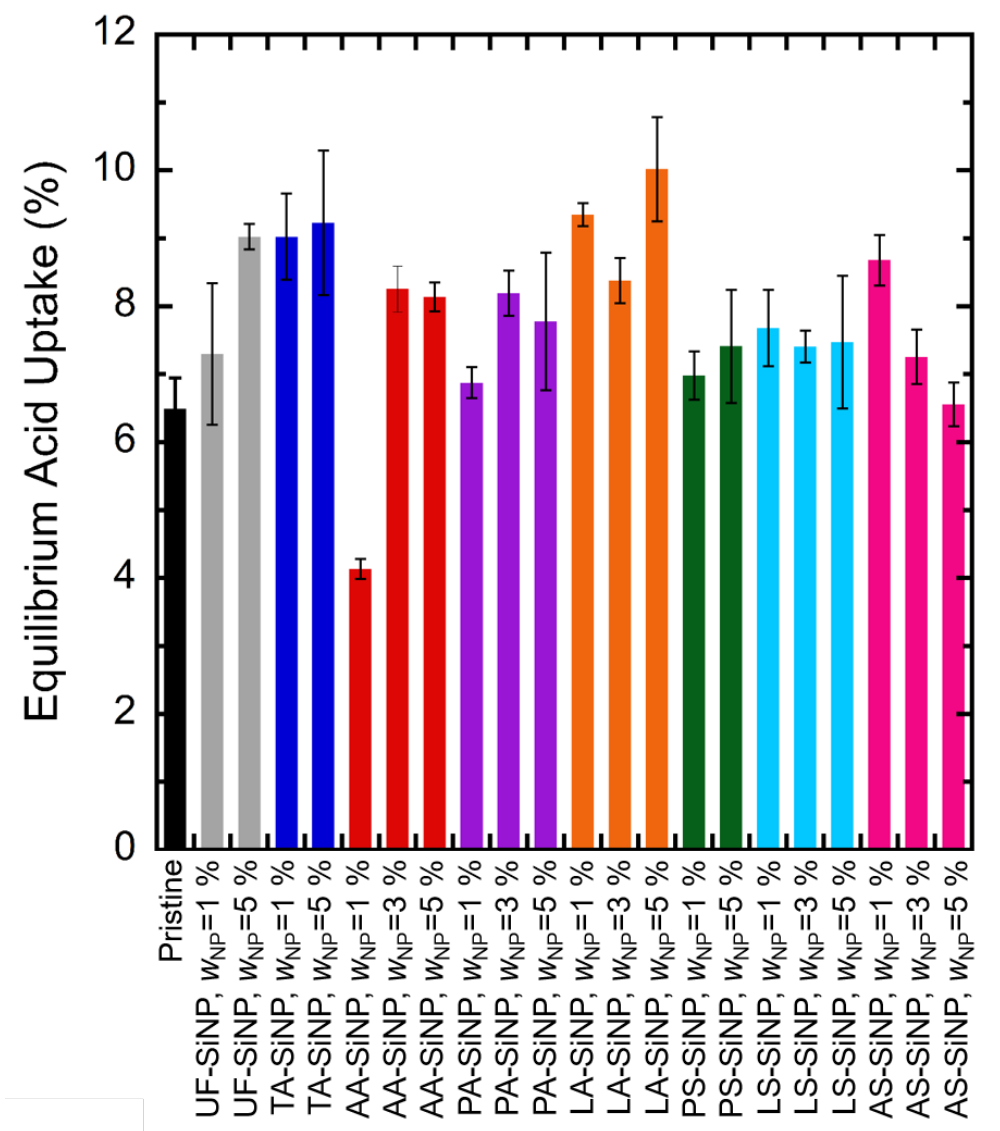

Figure S4. Equilibrium acid uptake of pristine Nafion compared to Nafion nanocomposite membranes of differing nanoparticle surface functionality and nanoparticle loading. Error bars represent the standard deviation of at least three repeat experiments.

Figure S4 shows the equilibrium acid uptake values for Nafion and Nafion nanocomposites containing SiNPs with various surface functionalities. The equilibrium acid uptake indicates the total amount of $3 \mathrm{~mol} \mathrm{~L}^{-1} \mathrm{H}_{2} \mathrm{SO}_{4}$ taken up by the membrane. This value can provide indirect information regarding the ionic network, as high values of equilibrium uptake indicate an increase in swelling (or size) of the ionic domains. The acid uptake experiments have been previously described $^{9}$ and the percent acid uptake is calculated by the following equation

$$
\% \text { uptake }=\frac{\left(\mathrm{m}_{\text {hydrated }}-\mathrm{m}_{\mathrm{dry}}\right)}{\mathrm{m}_{\mathrm{dry}}} \times 100 \%
$$


where $m_{\text {hydrated }}$ is the mass of the membrane in $g$ after immersing in $3 \mathrm{~mol} \mathrm{~L}^{-1}$ sulfuric acid for $24 \mathrm{~h}$. As seen from Figure S4, the equilibrium acid uptake of all nanocomposite membranes (except those containing AA-SiNP at $w_{\mathrm{NP}}=1 \%$ ) increased or remained similar to that of pristine Nafion, indicating that, on average, these membranes are more highly swollen that Nafion containing no SiNPs. 


\section{References}

(1) Liu, Y.-L.; Hsu, C.-Y.; Su, Y.-H.; Lai, J.-Y. Chitosan-Silica Complex Membranes from Sulfonic Acid Functionalized Silica Nanoparticles for Pervaporation Dehydration of Ethanol-Water Solutions. Biomacromolecules 2005, 6, 368-373.

(2) Lin, C.-H.; Yang, M.-C.; Wei, H.-J. Amino-Silica Modified Nafion Membrane for Vanadium Redox Flow Battery. J. Power Sources 2015, 282, 562-571.

(3) Gill, C.; Price, B.; Jones, C. Sulfonic Acid-Functionalized Silica-Coated Magnetic Nanoparticle Catalysts. J. Catal. 2007, 251, 145-152.

(4) Howarter, J. A.; Youngblood, J. P. Optimization of Silica Silanization by 3Aminopropyltriethoxysilane. Langmuir 2006, 22, 11142-11147.

(5) Kang, T.; Lee, J. H.; Oh, S.-G. Dispersion of Surface-Modified Silica Nanoparticles in Polyamide-Imide (PAI) Films for Enhanced Mechanical and Thermal Properties. J. Ind. Eng. Chem. 2017, 46, 289-297.

(6) Peña, L.; Xu, F.; Hohn, K. L.; Li, J.; Wang, D. Propyl-Sulfonic Acid Functionalized Nanoparticles as Catalyst for Pretreatment of Corn Stover. J. Biomater. Nanobiotechnology 2014, 05, 8-16.

(7) Safari, J.; Zarnegar, Z. An Environmentally Friendly Approach to the Green Synthesis of Azo Dyes in the Presence of Magnetic Solid Acid Catalysts. RSC Adv. 2015, 5, 1773817745.

(8) Liu, S.; Wang, L.; Ding, Y.; Liu, B.; Han, X.; Song, Y. Novel Sulfonated Poly (Ether Ether Keton)/Polyetherimide Acid-Base Blend Membranes for Vanadium Redox Flow Battery Applications. Electrochimica Acta 2014, 130, 90-96.

(9) Jansto, A.; Davis, E. M. Role of Surface Chemistry on Nanoparticle Dispersion and Vanadium Ion Crossover in Nafion Nanocomposite Membranes. ACS Appl. Mater. Interfaces 2018, 10, 36385-36397. 